\title{
Penicillinase Positive Staphylococcus
}

\section{Aureus}

National Cancer Institute

\section{Source}

National Cancer Institute. Penicillinase Positive Staphylococcus Aureus. NCI Thesaurus.

Code C124403.

A subgroup of $\mathrm{S}$. aureus bacteria that produce beta-lactamase (penicillinase) and are therefore resistant to beta-lactam (penicillin) antibiotics. 